\title{
Bowel perforation after single-dose activated charcoal
}

\author{
Jason P. Green, BSc, MD;* William McCauley, MD, MHPE ${ }^{\dagger}$
}

\begin{abstract}
Patients presenting to the emergency department (ED) after medication overdose are often given activated charcoal initially for gastrointestinal decontamination. Complications of charcoal are rare, but do occur. The following case describes a patient with pre-existing undiagnosed diverticular disease who developed sigmoid perforation after a single dose of activated charcoal, given without cathartic for a drug overdose. A literature search revealed no other cases of bowel perforation associated with single-dose activated charcoal. This case report discusses adverse effects associated with activated charcoal and the role of cathartics in gastrointestinal decontamination.
\end{abstract}

Key words: gastrointestinal decontamination, charcoal, sigmoid perforation

RÉSUMÉ

Les patients qui se présentent au service des urgences après une surdose reçoivent souvent du charbon activé au départ pour une décontamination gastro-intestinale. Les complications liées au charbon sont rares, mais peuvent tout de même se produire. Le cas suivant est celui d'un patient atteint d'une maladie diverticulaire pré-existante qui a été victime d'une perforation du sigmoïde après une dose unique de charbon activé donnée comme cathartique à la suite d'une surdose. Une recherche de la littérature n'a révélé aucun autre cas de perforation intestinale associée à une dose unique de charbon activé. La présente observation discute des effets indésirables liés au charbon activé et du rôle des cathartiques dans le cadre de la décontamination gastro-intestinale.

\section{Introduction}

Activated charcoal is a commonly used emergency department (ED) gastrointestinal (GI) decontamination agent. It is usually administered rapidly after ED presentation unless the drug or quantity of drug ingested is non-toxic, the drug does not bind to activated charcoal, or sufficient time has passed so that drug absorption is likely to be complete. $^{\prime}$

Reported adverse effects of activated charcoal include emesis, ${ }^{2,3}$ pulmonary aspiration, ${ }^{4-6}$ and GI obstruction ${ }^{2,3,7-12}$ or perforation. ${ }^{13-15}$ Bowel perforation is extremely rare, and we could find no cases associated with a single dose of $50 \mathrm{~g}$ of activated charcoal without sorbitol. This case report de-

*Department of Emergency Medicine, University of Calgary, Calgary, Alta. At the time of writing, Dr. Green was at Schulich School of Medicine and Dentistry, University of Western Ontario, London, Ont.

tDepartment of Emergency Medicine, London Health Sciences Centre and Division of Emergency Medicine, Schulich School of Medicine and Dentistry, University of Western Ontario, London, Ont.

Received: Nov. 14, 2005; revisions received: July 17, 2006; accepted: July 20, 2006

This article has been peer reviewed.

Can J Emerg Med 2006;8(5):358-60 
scribes a patient who suffered perforation of the sigmoid colon with charcoal peritonitis following the administration of a single dose of activated charcoal without cathartic.

\section{Case report}

A 49-year-old woman presented to the ED with slurred speech and unsteadiness. She reported ingesting unknown quantities of acetaminophen with codeine, Fiorinal ${ }^{\circledR}$ with codeine, zopiclone and temazepam at various times during the preceding 2-9 hours. The patient gave several different versions of what she had ingested and when they were ingested to the triage nurse, treating nurse and physician. Her past medical history included hypertension, hypercholesterolemia, occasional epigastric discomfort from gastresophageal reflux, and a (remote) partial hysterectomy for endometriosis. Her medications included esomeprazole, atorvastatin, indapamide and diltiazem.

On examination, her heart rate was 54 beats $/ \mathrm{min}$, blood pressure $125 / 70 \mathrm{~mm} \mathrm{Hg}$, respiratory rate 16 breaths/min, and oxygen saturation, $98 \%$ on room air. Her speech was slightly slurred; however the rest of the physical exam, including neurologic and abdominal examinations, were unremarkable.

Because of the possibility of a recent significant ingestion, she was given $50 \mathrm{~g}$ of activated charcoal by mouth, without sorbitol. Laboratory investigations were ordered, and the patient was observed on a cardiac monitor in the ED. Serum biochemistry, including creatinine, urea, glucose, electrolytes and osmolality, was normal. Ethanol, salicylate and acetaminophen levels were undetectable. Qualitative testing for tricyclic antidepressants was negative. Urine screening for opiates was not done.

After 2.5 hours of observation, she was judged to be medically stable with no suicidal ideation, and she was discharged from the ED in the care of family members, with arrangements for urgent outpatient crisis service follow-up. On the third day following discharge, she returned to the ED with increasing abdominal pain and obstipation despite having taken an over-the-counter laxative (bisacodyl). On examination her heart rate was 63 beats/min, blood pressure $141 / 93 \mathrm{~mm} \mathrm{Hg}$, respiratory rate 16 breaths/min, temperature $36.7^{\circ} \mathrm{C}$, and oxygen saturation $99 \%$ on room air. She was in obvious distress with a soft abdomen and tenderness in the lower quadrants, with stool and charcoal present on rectal examination. Bowel sounds were present. An intravenous was started, and a Fleet ${ }^{\circledR}$ enema was administered. Abdominal films performed following the Fleet enema showed air-fluid levels and free intraperitoneal air.

Urgent laparotomy revealed extensive gross fecal and charcoal peritonitis, and a 2-by-2-cm perforation in her sigmoid colon. A Hartmann's resection was performed. The surgical pathology report showed diverticular disease and a focal perforation near a diverticulum with evidence of acute and chronic inflammation.

\section{Discussion}

Although a 1997 Position Statement by the American Academy of Clinical Toxicology and the European Association of Poisons Centres and Clinical Toxicologists suggested that there was no published evidence that activated charcoal causes constipation, ${ }^{16}$ numerous case reports describe GI complications of activated charcoal, including constipation, diarrhea and emesis. ${ }^{2,3,7-9,13}$ There are at least 8 published cases of GI obstruction ${ }^{2,3,7-12}$ and 3 of GI perforation $^{13-15}$ in patients treated with activated charcoal; however, all of these were associated with either multiple doses of activated charcoal or GI instrumentation. We found no published reports of GI perforation after a single dose of activated charcoal.

In 1993, Mariani and Pook reported the case of a 35year-old woman who was brought to the ED after an overdose of clomipramine hydrochloride capsules. The patient underwent a difficult orogastric tube insertion and developed a GI perforation and charcoal peritonitis shortly after instillation of a single dose of activated charcoal; however, laparoscopic exploration failed to reveal the perforation site. The authors concluded that the perforation was not due to charcoal administration, but rather to direct trauma from the orogastric tube insertion or to retching during the tube placement. ${ }^{15}$

In 1998, Ross and colleagues described the case of a 35year-old woman who had ingested $4500 \mathrm{mg}$ of imipramine. The patient was treated with an unspecified amount of activated charcoal and sorbitol, and within 24 hours developed hemodynamic instability. Investigations revealed a dilated large bowel and pneumoperitoneum. Laparoscopic evaluation revealed dilatation from the right colon to the distal left colon and perforation of the midtransverse colon, but no evidence of obstruction. The authors proposed that the anticholinergic effects of imipramine led to toxic megacolon and perforation. ${ }^{14}$

Gomez and coworkers (1992) reported the case of a 39year-old woman who presented with lethargy and was found to have an elevated amitriptyline level. Her treatment included two 50-g doses of activated charcoal without cathartic, administered 4 hours apart. Four days later she developed abdominal discomfort, fever, peritoneal signs and leukocytosis. Laparotomy revealed a 4-cm perfo- 
ration in her sigmoid colon adjacent to a large charcoal mass. The authors concluded that multiple doses of activated charcoal and medication-induced bowel hypomotility were contributing factors. ${ }^{13}$

The 1997 Position Statement ${ }^{16}$ stated that, although activated charcoal has not been shown to improve clinical outcome, it may be beneficial if administered within an hour of toxic ingestion, which would justify its use in this case given uncertainty around the nature and timing of the ingestion. Previous literature suggests that cathartics may reduce GI transit time of the charcoal-drug complex, thus decrease the chance of drug absorption if unbinding from the charcoal occurs. ${ }^{17}$ However, in a 2004 Position Statement, the American Academy of Clinical Toxicology and the European Association of Poisons Centres and Clinical Toxicologists noted that cathartics have not been shown to decrease drug absorption, but that they do cause nausea, vomiting, abdominal cramps, diaphoresis, dehydration, transient hypotension, hypernatremia and hypermagnesemia. These organizations concluded that cathartic administration has not been shown to decrease morbidity from medication overdose and did not recommend it as a method of gut decontamination. ${ }^{18}$

In the case described here, our patient reported ingesting Fiorinal ${ }^{\circledR}$ with codeine and acetaminophen with codeine medications that can result in GI hypomotility and constipation. Her salicylate and acetaminophen levels were below detection levels; therefore, we can be confident that, if the patient ingested these compounds, she did not ingest sufficient amounts to cause toxicity. Her underlying diverticular disease with chronic inflammation, would have caused an underlying structural weakness in the colonic wall, perhaps predisposing to perforation, despite the lack of pain or other diverticular symptoms at the time of initial assessment.

\section{Conclusion}

Physicians should be aware that activated charcoal has the potential to cause bowel perforation - particularly in patients with underlying chronic disease.

Competing interests: None declared.

\section{References}

1. Bond GR. The role of activated charcoal and gastric emptying in gastrointestinal decontamination: a state-of-the-art review. Ann Emerg Med 2002;39:273-86.

2. Goulbourne KB, Cisek JE. Small-bowel obstruction secondary to activated charcoal and adhesions. Ann Emerg Med 1994;24: 108-10.
3. Watson WA, Cremer KF, Chapman JA. Gastrointestinal obstruction associated with multiple-dose activated charcoal. J Emerg Med 1986;4:401-7.

4. Dorrington CL, Johnson DW, Brant R. The frequency of complications associated with the use of multiple-dose activated charcoal. Ann Emerg Med 2003;41:370-7.

5. Benson B, VanAntwerq M, Hergott T. A fatality resulting from multiple dose activated charcoal therapy. Vet Hum Toxicol 1989;31:335.

6. Seger D. Single-dose activated charcoal — backup and reassess. J Toxicol Clin Toxicol 2004;42:101-10.

7. Merriman T, Stokes K. Small bowel obstruction secondary to administration of activated charcoal. Aust N Z J Surg 1995; 65:288-9.

8. Atkinson SW, Young Y, Trotter GA. Treatment with activated charcoal complicated by gastrointestinal obstruction requiring surgery. BMJ 1992;305:563.

9. Ray MJ, Padin DR, Condie JD, et al. Charcoal bezoar: smallbowel obstruction secondary to amitryptyline overdose therapy. Dig Dis Sci 1988;33:106-7.

10. Longdon P, Henderson A. Intestinal pseudo-obstruction following the use of enteral charcoal and sorbitol and mechanical ventilation with papaveretum sedation for theophylline poisoning. Drug Saf 1992;7:74-7.

11. Flores F, Battle WS. Intestinal obstruction secondary to activated charcoal. Contemp Surg 1987;30:57-9.

12. Anderson IM, Ware C. Drug points [letter]. BMJ 1987;294:578.

13. Gomez HF, Brent JA, Munoz DC, et al. Charcoal stercolith with intestinal perforation in a patient treated for amitriptyline ingestion. J Emerg Med 1992;12:57-60.

14. Ross JP, Small TR, Lepage PA. Imipramine overdose complicated by toxic megacolon. Am Surg 1998;64:242-4.

15. Mariani PJ, Pook N. Gastrointestinal tract perforation with charcoal peritoneum complicating orogastric intubation and lavage. Ann Emerg Med 1993;22:606-9.

16. American Academy of Clinical Toxicology and the European Association of Poisons Centres and Clinical Toxicologists. Single-dose activated charcoal [position statement]. Available at: www.clintox.org/Pos_Statements/Charcoal.html (accessed 2006 Aug 3).

17 Perry H, Shannon M. Emergency department gastrointestinal decontamination. Pediatr Ann 1996;25:19-26.

18. Position paper: cathartics [published erratum appears in J Toxicol Clin Toxicol 2004;42(7):1000]. J Toxicol Clin Toxicol 2004;42(3):243-53.

Correspondence to: Dr. W.A. McCauley, Department of Emergency Medicine, London Health Sciences Centre, 375 South St., London ON N6A 4G5 